\title{
TRABALHO ESCOLAR COM VOCABULÁRIO EM RELATÓRIOS DE ESTÁGIOS SUPERVISIONADOS EM ENSINO DE LÍNGUA INGLESA**
}

\author{
SCHOOLWORK WITH VOCABULARY IN SUPERVISED \\ INTERNSHIP REPORTS IN ENGLISH LANGUAGE TEACHING
}

\author{
Lívia Chaves de Melo* \\ Karylleila dos Santos Andrade \\ Wagner Rodrigues Silva
}

\section{RESUMO}

A partir da teoria lexical, identificamos e descrevemos alguns exercícios didáticos que focalizam a aquisição e ampliação do vocabulário em aulas de Língua Inglesa no contexto de instrução formal na disciplina de estágio supervisionado em Ensino de Língua Inglesa. Tais exercícios didáticos são utilizados por alunos-mestre na prática de estágio nas escolascampo. A análise dos dados mostrou que o ensino do vocabulário nos dados analisados ocorre de forma isolada, sem considerar o contexto de leitura de textos autênticos. O estudo do vocabulário específico voltado para a compreensão leitora geralmente não ocorre.

Palavras-chave: ensino de língua estrangeira; gênero; formação docente; interdisciplinaridade.

\section{ABSTRACT}

Based on lexical theory, this study identified and described didactic exercises that focus on vocabulary acquisition and improvement in English classes in the subject of supervised English teaching practice. Such exercises are used by student-teachers in their internship practice at schools. The analysis of data has shown that the teaching of vocabulary occurs as an isolated practice, without takink into consideration the reading context of authentic texts. The study of specific vocabulary focused on reading comprehension does not usually occur.

Keywords: foreign language teaching; genre; teacher education; interdisciplinary.

\footnotetext{
"CCAA, Araguaína (TO), Brasil. e-mail: liviachavesmelo@hotmail.com; UFT, Araguaína (TO), Brasil. e-mail: karylleila@uft.edu.br; UFT/CNPq, Araguaína (TO), Brasil. e-mail: wagnerodriguesilva@ hotmail.com

** Trabalho apresentado no VII Congresso Internacional da ABRALIN, na Universidade Federal do Paraná - UFPR. Uma versão preliminar deste texto foi publicada nos anais do referido evento.
} 
Having a big vocabulary does contribute to being a better reader. But being a good reader also contributes to having a bigger vocabulary. One of the main reasons is that better readers do a lot more reading. (Anderson, Wilson, \& Fielding, 1988, apud NAGY, 2005, p.34).

\section{INTRODUÇÃO}

A área de aquisição de vocabulário em ensino de Língua Inglesa tem despertado o nosso interesse, pois ainda são incipientes, no contexto brasileiro, pesquisas que apontem a importância do conhecimento lexical para o desenvolvimento da habilidade comunicativa. Neste trabalho, investigamos, no âmbito da teoria lexical, exercícios didáticos que compõem os relatórios de estágio supervisionado em Ensino de Língua Inglesa que focalizam a aquisição de palavras na língua estrangeira. Tais exercícios compõem os relatórios de estágio supervisionado, propostos como objetos de ensino em disciplinas de Investigação da Prática Pedagógica e Estágio Supervisionado em Lingua Inglesa: Língua e Literatura, elaborados por alunos-mestre, pertencentes ao curso de Licenciatura em Letras, no Campus Universitário de Araguaína, Universidade Federal do Tocantins - UFT ${ }^{1}$.

Investigamos os exercícios didáticos propostos por alunos-mestre em 10 (dez) relatórios de estágio de uma única turma de estágio em Ensino de Língua Inglesa, estágio III, apresentados como trabalhos escritos finais da disciplina focalizada nesta pesquisa, ofertada no primeiro semestre do ano de 2010. O propósito desta investigação é identificar e descrever os tipos de atividades didáticas sobre ensino de vocabulário que os alunos-mestre propõem durante as aulas de Língua Inglesa, ministradas por eles, nos estágios supervisionados.

Neste trabalho, utilizamos a metodologia da análise documental, informada pela metodologia da análise de conteúdo para a investigação dos dados. Destacamos, nos exercícios investigados, a ausência de uma proposta de ensino de língua estrangeira que tenha um enfoque na conscientização crítica dos aprendizes de segunda língua, conforme os próprios alunos-mestre manifestam nas primeiras seções dos relatórios de estágio, quando relatam e analisam experiências vivenciadas

\footnotetext{
1. Este trabalho faz parte da pesquisa "Relatórios de estágio supervisionado em ensino de língua inglesa: práticas auto-reflexivas de escrita", desenvolvida como trabalho de dissertação no Mestrado em Ensino de Língua e Literatura - MEL/UFT, pela primeira autora deste artigo. Contribui para os projetos de pesquisa "Formação Inicial de professores mediada pela escrita" (CNPq/CAPES 400458/2010-1) e "Implicações dos relatórios de estágio supervisionado para a formação inicial de professores" (CNPq 501123/2009-1), desenvolvidos dentre do grupo de pesquisa "Práticas de linguagens em estágios supervisionados" - PLES. (UFT/CNPq).
} 
na prática do estágio.

As análises dos exercícios didáticos investigados mostram que o trabalho com aquisição lexical, nas aulas de Língua Inglesa, restringe-se ao uso de dicionário a partir da transcrição e identificação de palavras e significados em Língua Materna, ou na Língua Inglesa, de forma descontextualizada. Usam-se também ilustrações para auxiliar a aquisição lexical. $\mathrm{O}$ estudo de léxico específico, voltado para a leitura de textos extensivos, normalmente, não ocorre. $\mathrm{O}$ elemento norteador das aulas é um foco mais no ensino da língua, e menos na compreensão leitora. Constatase, nesta análise, a reafirmação de uma postura tradicional do ensino de língua estrangeira, o que impossibilita uma defesa ou abordagem mais clara e objetiva quanto ao ensino do vocabulário como um meio de complementar e de ampliar o processo de construção de conhecimentos na língua-alvo, neste caso, o inglês.

Conforme observável na epígrafe deste artigo, Anderson, Wilson e Fielding (2005) usam o termo vocabulário para fazer referência a um conjunto de palavras que os indivíduos de uma determinada língua têm à sua disposição para expressarse, oralmente ou por escrito. É necessário explicitar, neste trabalho, a diferença entre léxico e vocabulário. Léxico é o inventário de todas as palavras que, num dado momento, estão à disposição do falante. São as palavras que ele pode, oportunamente, utilizar e compreender. Constituem o que denominamos de léxico individual. Vocabulário é o inventário das palavras efetivamente utilizadas pelo locutor num ato de fala preciso. Ou seja: pode ser compreendido como a atualização de certo número de palavras pertencentes ao léxico individual do locutor. Segundo Genouvrier e Peytard (1985, p. 279), é possível enumerar e inventariar as palavras diferentes que o aluno empregou numa atividade escrita ou oral, o que fornece uma imagem da riqueza do vocabulário do aluno naquele determinado momento, mas não pode senão dar apenas uma amostra do seu léxico.

O vocabulário e o léxico se encontram numa relação de inclusão. $\mathrm{O}$ primeiro é sempre parte, de dimensões variadas, conforme as solicitações de momento, do léxico individual, que, por sua vez, faz parte do léxico global. Isto quer dizer que o professor não tem como perceber a totalidade do léxico do seu aluno. Por outro lado, o aluno não tem como utilizar, no ato de fala, a totalidade de seu léxico. De qualquer modo, é preciso apontar que a riqueza do vocabulário, quantitativa e qualitativa, é função do léxico. Surge então um problema: como ampliar o léxico? como realizar seleções nesse léxico? Isto possibilita a abertura de dois caminhos: a) fornecer ao aluno um número de palavras tão diversificadas quanto possível, exigir dele um emprego sensato de todas as palavras adquiridas; b) fazer com que o léxico amplie e o vocabulário seja adequado quanto à seleção. 
É preciso, neste contexto, explicitar que 'palavra' é um termo ainda ambíguo na linguística. De qualquer modo, utilizaremos a referência de Basílio (2007, p.7) que afirma que palavras, ou itens lexicais, são os elementos básicos que utilizamos para formar enunciados. É nessa perspectiva que trabalharemos com a noção de aquisição do vocabulário.

A ampliação, o enriquecimento e a seleção exigidos pelo vocabulário não estão, infelizmente, sob controle do professor. O aluno, na sua função de locutor, é determinado pelas relações com os níveis socioculturais em que está em contato. Esses níveis demandam apelos, solicitações e influências diversas e, muitas vezes, divergentes, como é o caso do ambiente familiar e escolar.

Este texto está organizado em duas principais seções, além da introdução e considerações finais. Na primeira seção, denominada Pressupostos teórico-metodológicos, discutimos sobre a importância do uso de textos autênticos, encontrados nas diferentes esferas sociais que podem possibilitar ao aprendiz, compreender a palavra alvo em seu contexto real de uso. Discutimos também sobre a importância do trabalho com atividades de pré-leitura que explorem as palavras-chave do texto para a compreensão e interpretação leitora. A segunda seção, intitulada Análise dos dados, está organizada nas seguintes subseções: Ensino de itens lexicais isolados em relatórios de estágio; Ensino do vocabulário em relatórios de estágio por meio de código visual, Ensino do vocabulário por meio de produção escrita: uma tentativa de inovação. Na primeira subseção, discutimos sobre o uso de exercícios didáticos que ocorrem dissociados do texto, desconsiderando a abordagem comunicativa da língua alvo. Na segunda subseção, mostramos que o uso de figuras ilustrativas faz parte do processo ensino-aprendizagem dos exercícios investigados. Leituras prévias de diversos gêneros disponíveis em diferentes esferas sociais reconhecíveis, em que o campo lexical explorado fosse utilizado, não foram identificadas nos exercícios analisados. Na terceira subseção, mostramos atividades didáticas que, apesar de continuar no tradicionalismo ao mobilizar a escrita como pretexto para o emprego das questões linguísticas estudadas, essas podem ser consideradas como uma tentativa de inovação. Essas últimas podem ser caracterizadas pela tentativa de articulação entre a teoria estudada na universidade e a prática do estágio desenvolvida na escola-campo.

\section{PRESSUPOSTOS TEÓRICO-METODOLÓGICOS}

Palavras isoladas vêm a nossa mente quando nos referimos ao ensino do vocabulário. Porém, a partir da citação apresentada como epígrafe deste texto, 
depreendemos que o conhecimento de vasto léxico isolado não contribui para tornar-se um leitor ideal. No entanto, ler abundantemente permite aquisição do vocabulário de forma ampla.

Acreditamos que os conhecimentos linguísticos e gramaticais são empregados na comunicação pela mediação do léxico. Pesquisas recentes mostram que um erro gramatical não impede a comunicação, mas um erro no uso do vocabulário pode causar grandes desentendimentos (SOUSA, 2010). Dessa forma, é bastante comum o estudo do vocabulário ser o centro da aprendizagem no ensino de línguas, conforme demonstram vários estudos no Brasil (GATTOLIN, 2006; SCARAMUCCI e GATTOLIN, 2007; TOMITCH, 2009; PROCÓPIO e SOUZA, 2009; SOARES e CONCEIÇÃO, 2010, só para citar alguns) e no exterior (UR, 1996; SCHMITT, 2000; KAMIL e HIEBERT, 2005).

A aquisição do vocabulário não é uma habilidade que pode ser totalmente dominada, pois o léxico de uma língua viva está sempre em processo de formação. Devido às práticas sociais da linguagem, a todo o momento, novas palavras são incorporadas no idioma, ou mesmo, antigas palavras perdem ou ganham novos sentidos. Assim, a aprendizagem de novas palavras é algo sempre em processo de formação e expansão que se estende por toda a vida. Para compreender a complexidade das palavras e seus diversos significados, é necessário considerar o contexto sóciocultural de uso no texto, assim como apontam diversas pesquisas acadêmicas (WIDDOWSON, 2004; NAGY, 2005; SCOTT, 2005; só para citar alguns).

Um provável encaminhamento para um trabalho diferenciado com o uso do vocabulário em Língua Inglesa, ou em qualquer outra Língua Estrangeira, de maneira que proporcione aos estudantes uma aprendizagem significativa do vocabulário, é o uso extensivo de textos autênticos, encontrados nas diferentes esferas sociais dos aprendizes. Acreditamos ser uma oportunidade para o estudante compreender a palavra em seu contexto real de uso em que os significados das palavras precisam ser ensinados, abrangendo como estas estão relacionadas semanticamente e morfologicamente. Sobre essa questão, Kamil e Hiebert $(2005$, p.9) declaram:

Extensive reading is also one of the meanings by which students see vocabulary in rich contexts. According to the National Reading Panel, seeing vocabulary in the rich context provided by authentic texts rather than in isolation was one of the characteristics of instruction that produced robust vocabulary learning.

Para uma maior efetivação do ensino do vocabulário, não basta o professor introduzir palavras novas e importantes, e sim proporcionar meios para o estudante 
compreendê-las. Isso requer múltiplas exposições à palavra; informações contextuais sobre a definição da palavra; conhecer os sinônimos, antônimos e hipônimos; ter conhecimento de definição da categoria na qual a palavra se encaixa e comparar com palavras semelhantes; saber usar a palavra no momento e no contexto adequado; saber selecionar a palavra para o efeito de sentido pretendido. Cunningham (2005, p.46) apresenta dois mecanismos para tal efetivação: exposição às modalidades oral e escrita da língua. Cabe ainda salientar que o vocabulário pode ser adquirido de forma acidental ou indireta, pela exposição a palavras no contexto em que o aprendiz se insere, assim também como revelam muitos estudos sobre a aprendizagem lexical publicado fora contexto acadêmico brasileiro.

Nesse sentido, no ensino de Língua Inglesa, mais especificamente, é essencial incluir atividades de pré-leitura que explorem o método de palavras-chave (keyword method) de textos autênticos, ou seja, textos que não foram elaborados com o fim de ensinar a língua. Nestas, o uso de conjuntos de palavras de determinados campos léxico-semânticos poderá ser explorado, pois o vocabulário é um instrumento mediador para o domínio semântico. Estamos compreendendo campo léxicosemântico como unidades linguísticas lexicais que representam um conjunto de conceitos incluídos dentro de uma etiqueta que define o campo (FERREIRA, 2009, p. 38 apud MOUNIN, 1979).

Nas atividades de compreensão oral e escrita, a estratégia de inferência do significado de palavras desconhecidas será compreendida no contexto em que está inserida. Fornecer aos estudantes múltiplas exposições às palavras-chaves em outras situações de uso favorece a aquisição de novas palavras. Uma atitude que pode fazer diferença no desenvolvimento e ampliação do vocabulário não é aquela que diz respeito à de armazenamento forçada na memória, mas à que se traduz em um esforço criativo. A criatividade, neste contexto, pode facilitar a expressão e estimular aquilo que já foi aprendido. Deve-se ter em mente que o aluno já possui um vocabulário mínimo, que o mesmo já dispõe de um número de palavras aprendidas e apreendidas, e que poderá dispô-las no momento que em se expressar.

Conhecendo a realidade do ensino-aprendizagem de Língua Inglesa nas escolas públicas brasileiras, sabemos que os estudantes não mantêm um contato intenso com situações autênticas de comunicação com a língua em questão, nas esferas sóciais das quais fazem parte. Cabe ao mediador do ensino promover oportunidades de uso da língua em contextos diversos e significativos.

A perspectiva transdisciplinar da Linguística Aplicada, assumida neste trabalho, campo de investigação que transgride fronteiras disciplinares, poderá contribuir para avanços no ensino de vocabulário, esclarecendo contribuições da competência lexical para o ensino de línguas. 


\section{ANÁLISE DOS DADOS}

Nesta pesquisa, os exercícios didáticos analisados revelam como o vocabulário é trabalhado pelos alunos-mestre nas aulas de Língua Inglesa. A sequência de exercícios reproduzida, assim como os demais exemplos apresentados, é representativa do tipo de atividades pedagógicas que são propostas na prática do estágio em ensino de Língua Inglesa aqui focalizada.

Os exercícios didáticos investigados neste trabalho são apropriados e adaptados pelos alunos-mestre a partir de livros didáticos (LD) de Língua Inglesa, instrumentos para o ensino e aprendizagem da língua alvo, geralmente adotados pela escola-campo. O LD é utilizado pelos acadêmicos como fonte pedagógica para seleção de textos e exercícios. Além do uso do LD, os acadêmicos adicionam materiais de sua própria escolha, como revistas e jornais no trabalho com recortes; a internet para a coleta de atividades de diversos gêneros, tais como letras de músicas, passatempos, flashcards dentre outros.

Estamos compreendendo exercício didático e atividade didática como nomenclaturas que se distinguem. $\mathrm{O}$ primeiro é tido como uma estratégia de treino utilizado pelo professor para recapitular os conteúdos programáticos ensinados e verificar a aprendizagem do estudante. Um gênero escolarizado que não tem comprometimento com a formação para além da sala de aula, podendo impedir o desenvolvimento da autonomia e criatividade do estudante, assim como revela Cerqueira (2010). Enquanto que o termo atividade é algo que "ultrapassa a visão imediatista da sala de aula, refletindo-se na formação dos sujeitos, de uma forma mais ampla" (CERQUEIRA, 2010, p. 132). Destacamos que a atividade didática, diferentemente do exercício didático, leva em consideração o contexto sóciohistórico cultural em que o individuo está inserido.

Vale ainda destacar que o emprego de exercícios lúdicos do tipo motivador, descontraído e criativo, durante a prática de estágio supervisionado em ensino de Língua Inglesa tem recebido especial atenção pelos alunos-mestre, principalmente na focalização do ensino do vocabulário. O uso da estratégia lúdica proporciona prazer aos estudantes, durante a resolução dos exercícios de modo satisfatório, podendo contribuir para o desenvolvimento do processo de ensino-aprendizagem da língua alvo de modo mais divertido e prazeroso, colaborando para o enriquecimento do saber, o desenvolvimento cognitivo e social humano. Nossas investigações vêm apontando que o lúdico também é usado possivelmente para aliviar certas tensões que são carregadas pelo ser humano devido ao constante estresse do dia-a-dia (MELO, 2011). 
Para identificarmos os exemplos selecionados, utilizamos a seguinte sequência de informações: informante, estágio, ano letivo e semestre letivo (Informante 01, Estágio I, 2010.1, por exemplo).

\subsection{Ensino de itens lexicais isolados em relatórios de estágio}

Nesta seção, reproduziremos alguns exercícios didáticos que exploram o ensino do vocabulário, selecionados dos dados investigados. Tais exercícios não consideram o uso comunicativo em Língua Inglesa. As palavras estudadas ocorrem de forma isolada, dissociada do contexto sócio-interacional.

Nos Exercícios didáticos 01 e 02 reproduzidos adiante, os assuntos tematizados na aula de Língua Inglesa foram cores e animais. Como veremos, o propósito desses exercícios foi a tradução de palavras descontextualizadas, desconsiderando o uso de textos.

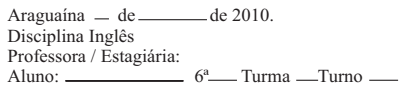

Exercises

Enumerate the second column with the correct translation.

$$
\begin{aligned}
& \square \text { Gray } \\
& \square \text { Black } \\
& \square \text { Orange } \\
& \square \text { Pink } \\
& \square \text { White } \\
& \square \text { Yellow } \\
& \square \text { Violet } \\
& \square \text { Purple } \\
& \square \text { Gold } \\
& \square \text { Silver } \\
& \square \text { Blue } \\
& \square \text { Green } \\
& \square \text { Red } \\
& \square \text { Brown }
\end{aligned}
$$

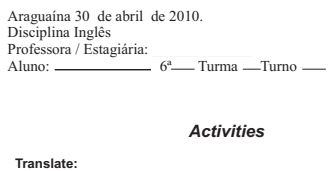

Translate:

Rabbit - horse - turtle - giraffe - chickem - cat - bird - elephant - dog tiger - kangaroo - fish - pig - monkey - duck - cow - zebra - mouse bear - lion

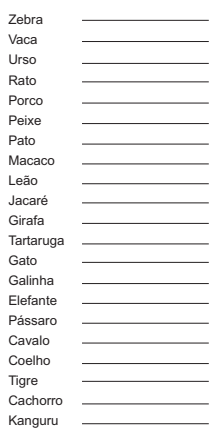

Exercícios didáticos 01 e 02. Informante 02, Estágio III, 2010.1

No Exercício didático 01, são apresentadas listas de palavras que identificam as cores. De um lado são apresentadas as denominações das cores em Língua Portuguesa, antecedidas por números que as identificam. Do outro lado da coluna, estas cores são mostradas em Língua Inglesa de maneira desordenada, cabendo ao estudante organizá-las, enumerando-as de acordo com a primeira coluna. Este tipo 
de exercício não está relacionado a uma situação interativa significativa. Sua função é a memorização mecânica, não ajudando na aprendizagem de uma segunda língua, pois palavras memorizadas são rapidamente esquecidas.

Já no Exercício didático 02, é apresentado o campo lexical dos animais em língua inglesa. Em seguida, é apresentada uma coluna com os nomes dos animais em língua portuguesa, acompanhadas por espaços vazios. Supõe-se que os espaços deveriam ser preenchidos com a palavra em língua inglesa correspondente, pois o comando proposto é apenas traduzir. Como perceptível, o campo lexical dos animais selvagens e o campo lexical dos animais domésticos aparecem misturados, não havendo uma distinção entre ambos. Vale destacar que a palavra jacaré aparece apenas em português juntamente com os demais itens lexicais e não em inglês (alligator). As listas de palavras podem ser aproveitadas significativamente quando selecionadas por temas ou tópicos contextualizados.

Ainda sobre os Exercícios didáticos 01 e 02, identificamos no mesmo relatório de estágio um bilhete da professora orientadora $(\mathrm{PO})$, responsável pela disciplina de estágio no âmbito acadêmico. No bilhete, é apresentada uma reflexão-crítica sobre a elaboração do relatório, sobre as atividades utilizadas durante a prática na escola-campo, elogios e lamentos. A PO questiona o seguinte: citaram o conteúdo trabalbado, mas foi apenas vocabulário? Não teve nenbuma estrutura linguística? Neste enunciado, observamos que o uso do articulador discursivo-argumentativo mas convoca o aluno-mestre a concordar com a comprovação de que foi trabalhado unicamente o ensino do vocabulário, o que é reforçado pelo advérbio de exclusão apenas. Enquanto que as formas linguísticas de negação não e nenbuma, apresentadas na expressão (não teve nenbuma estrutura linguística), aponta a preocupação da PO por não ter sido explorado o ensino gramatical da língua em foco. No encerramento do bilhete, o tratamento dado ao ensino do vocabulário é caracterizado pelo uso do advérbio majoritariamente. A PO revela um sentimento emotivo de lamento e descontentamento em relação ao ensino do vocabulário proposto, ao fazer uso de advérbio modalizador afetivo (NEVES, 2000, p.238) infelizmente, demonstrando o emprego do ensino de vocabulário que ocorreu de forma tradicional. 


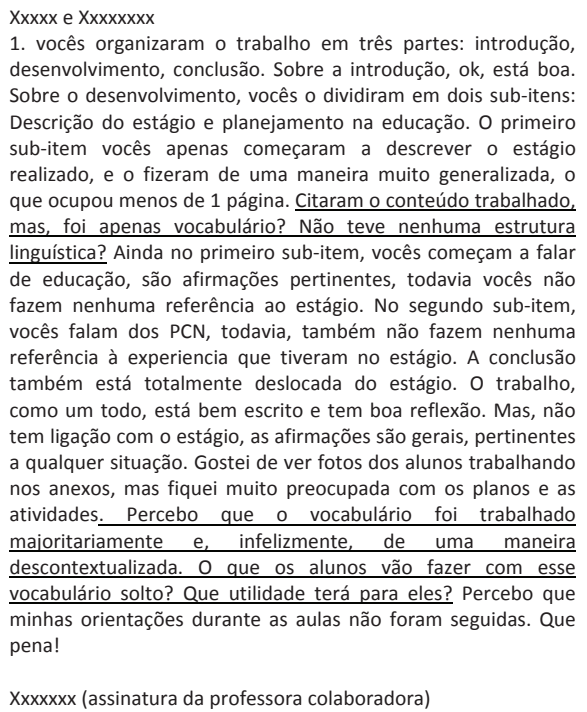

Bilhete. Informante 02, Estágio III, 2010.1 (grifos do autor)

Dentre os relatórios de estágio de Língua Inglesa por nós investigados, dentre os anos de 2007.1 a 2010.2, apenas no estágio III do ano 2010.1, verificamos o uso do gênero bilhete como instrumento de intervenção manuscrito. Este gênero pode estabelecer um canal de comunicação entre professor orientador e alunomestre, aproximando-os pelo diálogo. Além do mais, é um instrumento que, se bem utilizado, poderá orientar a reescrita/refacção de um novo texto conforme atestam Gonçalves e Bazarim (2009).

Na primeira parte do Exercício didático 03 mostrado adiante, aplicado a uma turma de $6^{\circ}$ ano do Ensino Fundamental, observa-se a presença de uma imagem que será identificada mais visivelmente a partir de sua pintura com algumas cores sugeridas em inglês. O comando da atividade é o seguinte: Paint the number and find the Picture. Provavelmente, os nomes das cores exigidas no exercício, tais como, brwon (sic), red, green, yellow, já tenham sido estudados em outras aulas de Língua Inglesa. Cada parte da imagem contém um número que corresponde a uma cor. A título de exemplo, o espaço da imagem em que está o número 1 deve ser colorido com a cor brown, explicitada em inglês no início da imagem. 


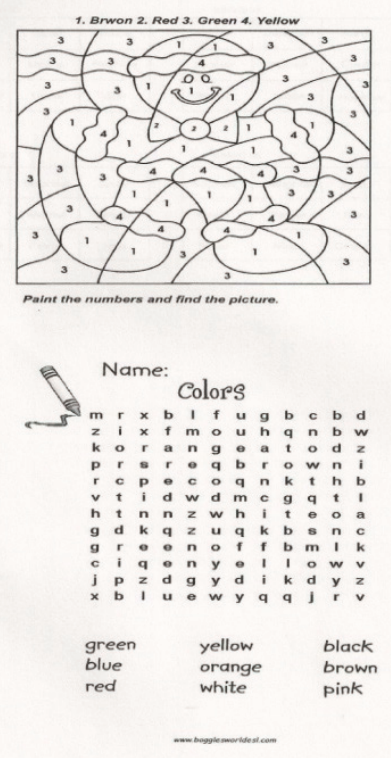

Exercício didático 03. Informante 03, Estágio III, 2010.1

$\mathrm{Na}$ segunda parte do Exercício didático 03, não é apresentado ao aprendiz um comando orientador para seu desenvolvimento. É um exercício que requer explicações orais do professor durante seu desenvolvimento. Neste, aparece a palavra name seguida de um espaço vazio, provavelmente, um espaço para o estudante identificar seu nome. Em seguida, a palavra colors é exposta, seguida por um quadro que se dá a conhecer que seja o gênero Word search, um passatempo bastante usado no ensino de língua estrangeira. Abaixo, são identificadas em inglês algumas cores, tais como: green, blue, red, yellow, orange, white, black, brown e pink. Espera-se que, neste tipo de exercício, o estudante deve procurar as palavras exibidas e colori-las com as cores correspondentes.

Como podemos verificar atentamente no exercício didático ilustrado, caso o estudante observe com mais atenção a grafia da palavra marrom, apresentada no primeiro momento da atividade (brwon) e no segundo momento (brown), poderá ficar meio desorientado para identificar qual a forma correta da palavra marrom em inglês. Como perceptível, o número quinze que aparece no canto esquerdo do exercício didático, comprova que o mesmo fora retirado de um livro didático para o ensino de Língua Inglesa. 
Nos dois momentos do Exercício didático 03, explora-se uma prática pedagógica lúdica, o que poderá proporcionar uma maior interação e motivação entre os aprendizes da língua em questão, os quais podem ficar mais interessados em assistir as aulas, tornando o processo ensino-aprendizagem mais significativo e prazeroso. No entanto, em nenhum momento do exercício proposto, verificamos o trabalho com uso de textos, em que as palavras-alvo apareçam. Dessa forma, apesar de o exercício proposto ser inovador ao utilizar a ferramenta lúdica, este não considera o uso comunicativo em Língua Inglesa. Percebemos que o ensino de vocabulário ocorre de forma isolada do contexto sócio-interacional.

A perspectiva sócio-interacionaista permite ao professor observar com mais atenção a participação dos alunos e re/avaliar o envolvimento discursivo em sala de aula, tendo em vista atividades textuais com foco na interação verbal. Esperase atitude, o aluno deverá ser ativo, organizar o pensamento a fim de produzir sentidos, inferir, utilizando-se dos conhecimentos adquiridos anteriormente.

Sobre esta questão, Bezerra (1999, apud GATTOLIN, 2006, p.141) propõe o seguinte:

O vocabulário deve ser ensinado de forma ampla, associado ao texto, desde os primeiros anos escolares de modo que os alunos se familiarizem com as novas palavras e armazenem-nas em suas memórias, através de seus esquemas cognitivos, que são formados com experiências sócio-culturais.

Os autores nos chamam a atenção para que essa discussão não seja pautada no teste de conhecimentos linguísticos, discursivos e gramaticais de um texto, mas, pelo contrário, que se verifique se o aluno, de fato, está produzindo e construindo significados no processo de interação com textos. O que percebemos, entretanto, é que esta abordagem sócio-interacional da linguagem tem sido pouco difundida no que se refere ao ensino e aquisição do vocabulário. Optar por atividades que promovam a memorização e oportunizar que os próprios alunos, dentro e fora da escola, produzam sentido pode ser bem mais atrativo.

A partir da análise do exercício ilustrado acima percebemos que os itens lexicais estudados serão adquiridos apenas parcialmente, pois não fora permitido o emprego destes itens em práticas escolares de leitura, escuta e produção textual.

\subsection{Ensino do vocabulário em relatórios de estágio por meio de código visual}

Os dados investigados nesta pesquisa revelam que o ensino do vocabulário, nas aulas de Língua Inglesa, geralmente está associado à imagem correspondente da 
palavra, ou seja, por meio do código visual. Inegavelmente, esta estratégia auxilia na aprendizagem lexical, pois a visualização, ao fazer parte do processo de ensino, poderá contribuir para a assimilação das novas palavras estudadas de maneira mais estimulante e mais concreta, tornando as atividades mais dinâmicas, favorecendo a aquisição do conhecimento lexical. Vejamos alguns exercícios didáticos aplicados por alunos-mestre na prática do estágio supervisionado em que poderemos verificar o uso de tal estratégia:

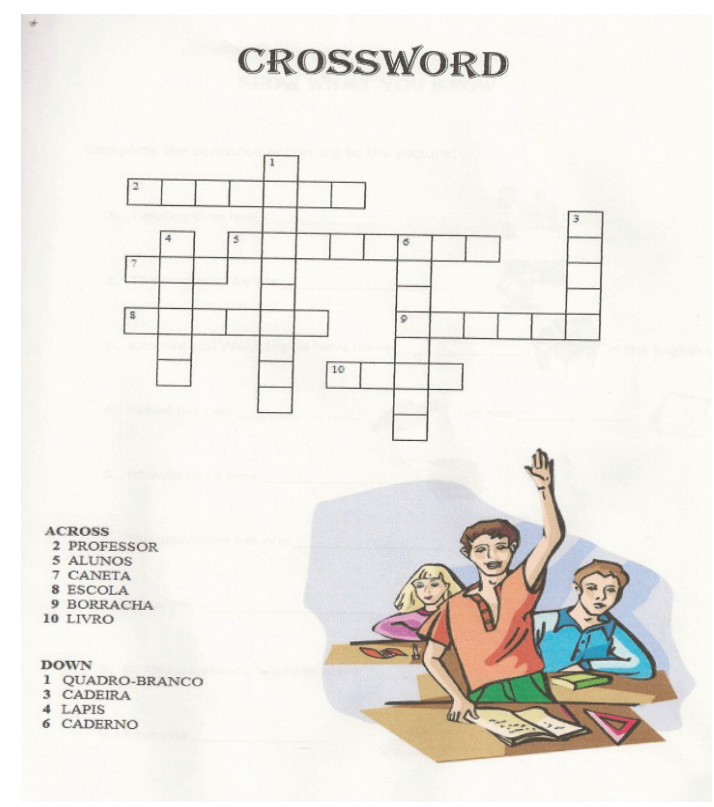

Exercício didático 04. Informante 04, Estágio III, 2010.1

No Exercício didático 04, reproduzido acima, é apresentado o uso do gênero crossword. Um jogo linguístico em que se fornece a definição da palavra, esperando que o jogador dê a palavra definida. No contexto pedagógico, este exercício lúdico permite aos estudantes revisarem e exercitarem o conteúdo trabalhado. É uma estratégia que pode facilitar o processo de ensino-aprendizagem podendo proporcionar um ensino mais dinâmico e divertido. Neste gênero, as palavras se entrecruzam horizontal e verticalmente, criando desafios que despertam no aluno o interesse em querer vencê-los. $\mathrm{O}$ uso dessa estratégia didática nas aulas de Língua Inglesa, se bem utilizado, poderá contribuir para o professor identificar as dificuldades de seus alunos com relação ao conteúdo trabalhado. Ser um sujeito 
ativo, neste tipo de atividade, facilita seu desempenho na construção de sentidos. Ele deve ser capaz de mobilizar o vocabulário já armazenado com o que ele deverá adquirir. Para tanto, o conhecimento de mundo e linguístico, associados às noções de campos lexicais e semânticos, poderá servir de suporte.

Ainda sobre o mesmo exercício, podemos verificar que as palavras que foram sugeridas para serem colocadas nos espaços adequados, aparecem em língua portuguesa, mas devem ser traduzidas para a lingua inglesa. São palavras relacionadas ao campo-lexical escola. Cumpre-nos destacar que o exercício didático mostrado, possivelmente, foi elaborado pelo próprio aluno-mestre, pois ao preenchermos os espaços vazios, verificamos alguns problemas para a escrita da palavra em inglês, tais como: o espaço preenchido com a letra $L$ da palavra blackboard (palavra 1), impediu a formação da palavra teacher (palavra 2), pois o espaço para a letra $H$ já havia sido ocupado pela letra $L$ de blackboard. O mesmo ocorre com a palavra students (palavra 5). Não foi possível formar a palavra students, pois o quadrinho que deveria ser colocado a letra $T$ já havia sido preenchido com a letra $C$ de blackboard. Acreditamos que propor uma descrição da imagem que aparece no exercício, por meio de uma pequena produção escrita, o vocabulário estudado poderia ser utilizado de forma contextualizada. Podemos afirmar ainda que, no exercício ilustrado, focalizase na significação quantitativa de determinado número de palavras, e apenas um significado de cada palavra é explorado.

No Exercício didático 05, reproduzido adiante, são apresentadas sentenças incompletas. Para que estas tenham um sentido coerente, cabe ao estudante completá-las de acordo com a imagem adequada. Como no Exercício didático 04, o campo-lexical escola também é o foco da proposta aplicada. Verifica-se no exercício o emprego do recurso figuras ilustrativas que auxiliam na aquisição do vocabulário em língua inglesa. Para o desenvolvimento deste exercício não foram consideradas leituras prévias de textos autênticos em que o campo-lexical explorado fosse utilizado, assim também como em outros exercícios já analisados neste trabalho. 


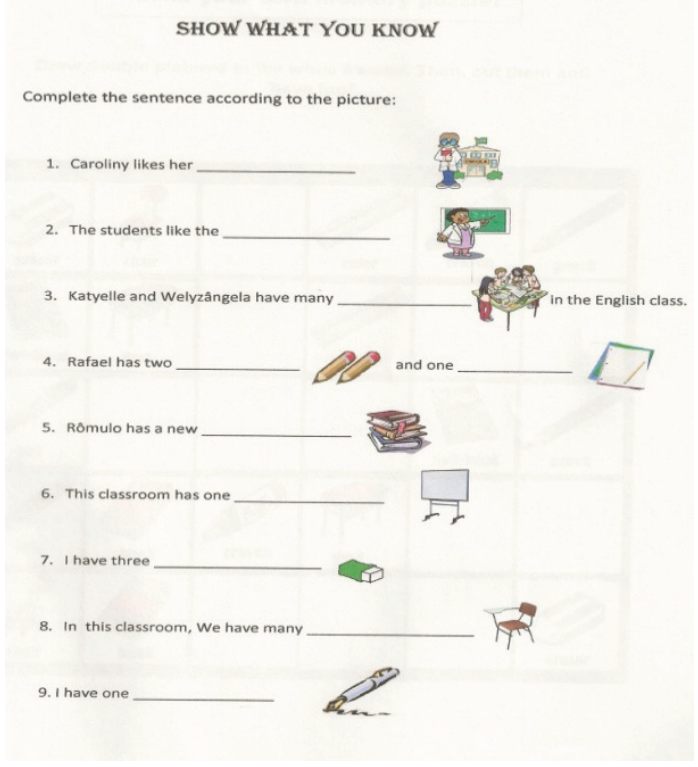

Exercício didático 05. Informante 04, Estágio III, 2010.1

Apresentamos a seguir uma passagem reproduzida do relatório de estágio do mesmo aluno-mestre que aplicou os Exercícios didáticos 04 e 05 em que é descrito o modo como foi estudado o conteúdo explorado, durante as aulas de língua inglesa.

Em primeira instância, trabalhamos com as turmas um vocabulário novo e contextualizado ao meio em que eles se encontram. Trabalhamos com eles algumas palavras relacionadas à escola, sem ignorar, é claro, aquilo que eles já conheciam e acrescentando-lhes um novo vocábulo antes não usado.

Percebemos que os alunos conheciam muitas palavras e que até as que não conheciam, tinham aprendido muito rapidamente em sala de aula. Isso pode ser explicado pelo fato de que eles perceberam que podiam usar aquelas palavras no seu dia-a-dia, isto é, aquilo que era para eles algo muito próximo, muito real. (Informante 04, Estágio III, 2010.1)

Conforme verificamos na passagem selecionada, o campo lexical da palavra escola foi o conteúdo aplicado (Trabalhamos com eles algumas palavras relacionadas à escola). Este conteúdo foi considerado novo para os estudantes, ou seja, um assunto que ainda não havia sido focalizado em momentos anteriores. $\mathrm{O}$ aluno-mestre utiliza os modificadores contextualizado e novo para caracterizar o vocabulário aplicado. O trabalho de forma contextualizada conforme depreendido na passagem é considerar o meio em que o estudante se encontra, provavelmente fazendo referência aos 
objetos concretos existentes na própria sala de aula; considerar o conhecimento de mundo do aprendiz (sem ignorar, é claro, aquilo que eles já conbeciam; Percebemos que os alunos conbeciam muitas palavras). Ainda na mesma passagem, o modificador contextualizado também é compreendido como usar o vocabulário estudado em situações reais e autênticas de uso da língua (eles perceberam que podiam usar aquelas palavras no seu dia-a-dia). Os termos que eram desconhecidos pelos aprendizes, conforme descritos foram acrescentados durante as aulas ministradas pelos acadêmicos (acrescentando-lhes um novo vocábulo antes não usado).

$\mathrm{Na}$ passagem analisada, não foi possível identificarmos se a maneira como o aluno-mestre compreende o trabalho contextualizado é uma prática excessivamente escolarizada, ou mesmo, um trabalho contextualizado com gêneros discursivos, utilizados na mediação do conhecimento, potencializadores do ensino-aprendizagem dispostos em circunstancias reconhecíveis. Como não acompanhamos a prática do estágio focalizado, tivemos acesso apenas aos documentos que aqui investigamos. No entanto, além dos dados mencionados, o contexto no qual estamos inseridos nos permite construir algumas suposições na tentativa de recuperar algumas informações outrora não mencionadas², assim como nos esclarece Widdowson (2004).

\subsection{0 ensino do vocabulário por meio de produção escrita: uma tentativa de inovação}

Nesta seção apresentamos uma atividade didática em que acreditamos que o aluno-mestre contextualiza as palavras estudadas por meio de exercícios de escrita. Mesmo não sendo o ensino lexical o foco da atividade, e sim o estudo da forma linguística do verbo to be, o aluno-mestre conseguiu construir situações reais de uso da língua em que o verbo to be é empregado na escrita pela mediação do vocabulário.

Selecionamos a seguir, uma passagem do relatório de estágio em que o aluno-mestre denominado por nós de Informante 05, descreve como foi desenvolvida a atividade didática proposta.

2. Estamos nos referindo à disciplina de Estágio em Ensino, vinculada ao Mestrado em Ensino de Língua e Literatura - MELL/UFT. Nesta disciplina, a primeira autora deste texto ministrou aulas na disciplina de Investigação da Prática Pedagógica e Estágio Supervisionado em Lingua Inglesa: Língua e Literatura I e II, sob a orientação da professora responsável pela disciplina, no segundo semestre de 2010. A referida disciplina pertence à licenciatura em Letras, do Campus Universitário de Araguaína, Universidade Federal do Tocantins - UFT. 
Nas aulas sobre o verbo to be, utilizamos recortes de celebridades e, ao apresentarmos questionamos a respeito de algumas características físicas e psicológicas. Por exemplo, perguntamos se a pessoa era alta, magra, cor dos cabelos, se na figura estava feliz, triste, brava etc.

À medida que os alunos iam caracterizando as celebridades, íamos tomando nota das palavras em inglês, para que, juntos pudéssemos memorizá-las e posteriormente montarmos frases com essas palavras. Valério (2005:104) ressalta que as características formais de uma frase são imprescindíveis quanto às situações nas quais o uso de tal frase é apropriado.

Diante dessa afirmação achamos pertinente tanto trabalhar a pronuncia dos alunos como também partimos explorarmos outro método de ensino, no caso, a produção de pequenos textos.

Após a explicação das formas do verbo to be, distribuímos revistas para que os alunos pudessem produzir pequenas frases. Neles, constariam características físicas e psicológicas das pessoas bem como o uso do verbo to be nas formas afirmativa e negativa. Através da participação da turma em forma de perguntas demonstrando certo esforço em produzir, nos fez perceber que o professor precisa estar atento às estratégias que estimulem o aprendizado de seus alunos.

No tocante à produção escrita, Silva \& Jorge (2005) salientam que apesar de haver dificuldades de se escrever e se ensinar a escrever em uma Língua Estrangeira, devemos reconhecer essa habilidade como sendo indispensável para a formação dos educandos. As mesmas corroboram ainda que as atividades de escrita são instrumentos que promovem aprendizagem da língua, consolidando assim as novas estruturas e vocabulários adquiridos. (Informante 05, Estágio III, 2010.1)

Como descrito na passagem textual selecionada acima, nas aulas práticas de estágio de ensino de língua inglesa em que o conteúdo sobre o verbo to be foi explorado, o aluno-mestre utilizou fotos selecionadas de revistas de algumas celebridades. Foi perguntado aos estudantes sobre as características físicas e psicológicas das celebridades apresentadas. Os adjetivos em inglês também foram explorados, pois, conforme revela o trecho selecionado, as características sugeridas eram listadas, provavelmente na lousa. Em seguida, estas palavras eram memorizadas (À medida que os alunos iam caracterizando as celebridades, íamos tomando nota das palavras em inglês, para que, juntos pudéssemos memorizá-las e posteriormente montarmos frases com essas palavras). Após, a memorização das palavras listadas, os estudantes eram orientados a elaborarem frases, possivelmente com a mediação do aluno-mestre.

Em seguida, foi trabalhada a pronúncia em inglês das palavras e a produção escrita (achamos pertinente tanto trabalbar a pronuncia dos alunos como também partimos explorarmos outro método de ensino, no caso, a produção de pequenos textos). Sobre a pronúncia na aula de Língua Inglesa como Língua Estrangeira, este é um componente essencial para a competência comunicativa, conforme Morley (1994, p.1 apud JUNIOR, 2010, 
p.750). Esta habilidade, geralmente é negligenciada nas aulas de línguas, e quando ocorre, tem recebido poucos créditos, pois os professores sentem que não têm tempo suficiente para treinar a pronúncia. No entanto, a pesquisa de Júnior (2010, p. 767) mostra que não bastam aulas prolongadas de pronúncia, ou mesmo aulas extracurriculares, mas a incorporação da prática fonético-fonológico, mesmo que por pouco tempo. Na passagem ilustrada, observamos que o aluno-mestre nos leva a compreender que mobilizou a prática fonético-fonológica no desenvolvimento do estágio.

Sobre a produção escrita, o aluno-mestre define esta habilidade como um instrumento que fomenta a aprendizagem da língua alvo, permitindo o emprego das unidades menores da língua e do novo item lexical adquirido, conforme predicação atribuída (as atividades de escrita são instrumentos que promovem aprendizagem da lingua, consolidando assim as novas estruturas e vocabulários adquiridos)

Acreditamos que as atividades não são "instrumentos", conforme termo atribuído no trecho selecionado, mas "estratégias pedagógicas" que acontecem por meio de instrumentos mediadores conforme os estudos propostos na abordagem sociointeracionista vygotskiana e bakhtiniana.

Vejamos dois exemplos da atividade proposta:
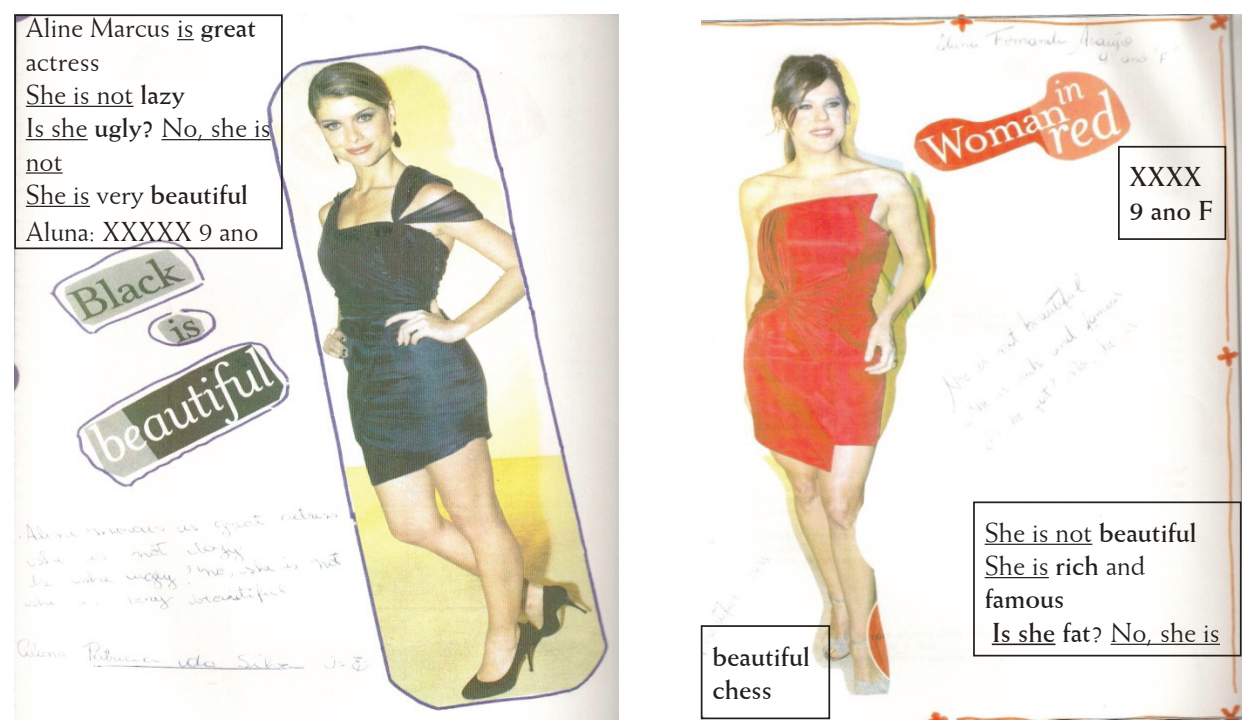

Exercícios didáticos 06 e 07. Informante 05, Estágio III, 2010.1 
A produção escrita desenvolvida nas atividades didáticas acima ilustradas limita-se ao uso do verbo to be nas formas afirmativa (Aline Marcus is great actrees; She is very beautiful; She is rich), negativa (She is not lazy; No, she is not; She is not beautiful; No, she is) e interrogativa (Is she ugly?; Is she fat?), além do uso de alguns adjetivos (beautiful; rich; lazy; ugly; fat). É uma escrita artificial apenas com a finalidade escolar, não permitindo o desenvolvimento da autonomia do estudante em ajustar-se a um contexto de comunicação social mais amplo. Nestes exercícios, o mediador do ensino poderá chamar a atenção dos estudantes para os usos dos antônimos beautiful e ugly.

A atividade didática analisada pode ser comparada às técnicas tradicionais ao mobilizar a escrita como pretexto para empregar as questões linguísticas estudadas. No entanto, são, a priori, consideradas inovadoras pela escolha da estratégia didática utilizada. Raramente encontram-se atividades de produção escrita nos documentos analisados em nossa pesquisa. Sobre a inovação, em Signorini (2007, p. 9), observa-se que inovar não significa somente mudar, progredir, ou mesmo modernizar. Por inovação, a autora compreende as tentativas de deslocamento das formas rotineiras de proceder ou agir, as quais não mais respondem às demandas sociais vigentes. Dessa forma, a inovação do ensino é caracterizada por avanços. Pode-se inovar nas aulas de línguas, criando situações de produção escrita real, mobilizando diversos gêneros textuais ou discursivos que possibilitem a criação de uma situação comunicativa mais significativa.

No exercício didático apresentado adiante, o aluno-mestre tenta inovar sua aula, trabalhando com o gênero tirinha. Apesar de o texto ter sido retirado de um livro didático qualquer, pode ser considerado um texto autêntico. No entanto, as questões propostas para serem resolvidas, estão fundamentadas no funcionamento de itens gramaticais. Em nenhum momento, foi considerada a construção de sentido para o texto, artificializando o ensino, distanciando as práticas sociais vivenciadas pelo aluno. Essa prática pode impedir o desenvolvimento sócio-cultural, cognitivo e linguístico do aluno. 
2) Look to Garfield and do as the example. Answer if you like or dislike.
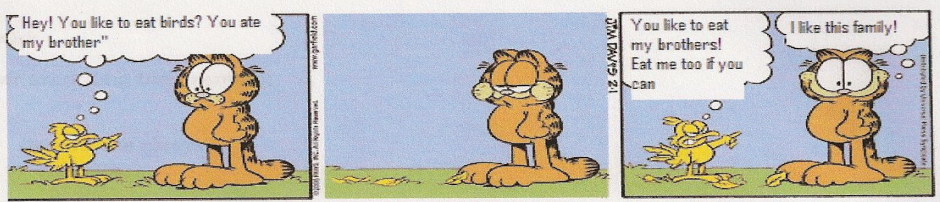

\section{New Words}

Things - coisas

to dance- dançar

to wash the dishes - lavar a louça

go to shop - ir às compras

to read-ler

to talk - converser

to pay bills - pagar as contas

to walk-caminhar

to ride in bike - andar de bicicleta

to eat vegetables - comer vegetais

THINGS THAT I LIKE AND I DON'T LIKE

a. I like to dance.

Eu gosto de dançar.

I don't like to dance.

Eu não gosto de dançar.

b.

c.

d.

e.

f.

9:

h.

\section{Exercício didático 08. Informante 06, Estágio III, 2010.1}

Após a apresentação da tirinha, aparece logo abaixo do exercício didático uma lista com algumas palavras em língua inglesa e seus respectivos significados em língua portuguesa. A lista de palavras não corresponde às palavras-chave do texto. Tais palavras são pretextos para o estudante formar frases usando a forma I like e I don't like. Para melhor visualização da tirinha, reproduziremos o texto adiante. 


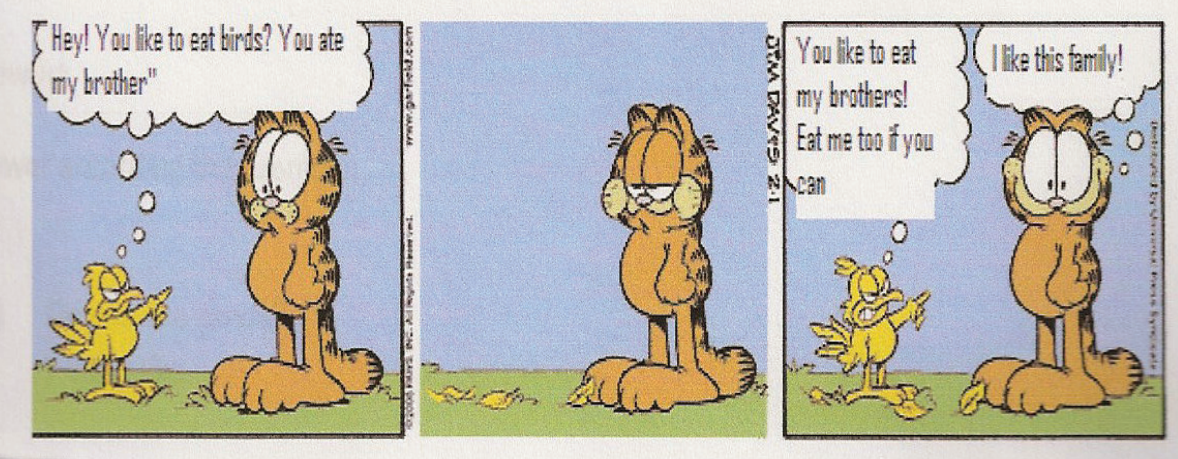

$\mathrm{Na}$ tirinha reproduzida, temos imagens de um pequeno passarinho amarelo irritado com o gato Garfield, como verificado em suas expressões faciais e gestuais ao apresentar o dedinho levantado e o biquinho encurvado, possivelmente como uma forma de provocar/ofender o gato laranjado e listrado, conhecido popularmente como guloso e preguiçoso. No primeiro quadro, o passarinho, usa a interjeição Hey! e questiona de forma informal se o felino gosta de comer passarinhos (You like to eat birds?), afirmando que ele havia comido seu irmão (You ate my brother).

No segundo quadro da tirinha, são apresentadas algumas penas de ave no chão. Garfield mostra-se com enormes bochechas como se estivesse mastigando, dando-nos a perceber que havia comido o passarinho irritado. Na última imagem, visualizamos outro passarinho ainda mais irritado que o primeiro, demonstrando raiva excessiva, o que é mostrado através dos dentes serrados e face contorcida. Este desafia o felino laranjado a comê-lo já que o mesmo adora alimentar-se dos seus irmãozinhos (You like to eat my brothers! Eat me too if you can). Com isso, Garfield exibe enorme contentamento, este apresenta belo sorriso e olhos grandes, afirmando que gosta/adora a família dos passarinhos amarelos (I like this family!). A última fala da tirinha leva-nos a depreender que Garfield comerá mais uma ave. O segundo irmão da mesma família do pequeno passarinho amarelo irritado.

Para o aluno inferir que Garlfield comeu o passarinho mostrado no primeiro quadro, ele terá que fazer a leitura da segunda imagem, pois nesta não é apresentado texto escrito, apenas o texto imagético. Além de entender o conteúdo escrito que aparece na tirinha, o aluno/leitor necessita compreender os elementos imagísticos do gênero tirinha. Por exemplo, o fato de que os desenhos dos balões também têm significados e que os mesmos ajudam o leitor a identificar as relações ideogramáticas entre imagem e conteúdo expresso. 
A tirinha apresentada usa uma situação natural de comunicação, permitindo a construção de um processo de significados das informações registradas na forma escrita, processamento denominado bottom-up. O processamento nomeado top-down que consiste em acionar o conhecimento de mundo (background knowledge), construído no contexto sociocultural também é acionado, portanto, este gênero é um texto autêntico elaborado para satisfazer um propósito humorístico.

Ainda sobre a tirinha ilustrada acima, esta pode ser utilizada como um pretexto para trabalhar o ensino do vocabulário com os aprendizes de língua inglesa. Destacamos que, após o trabalho de construção de sentido que considere os elementos pragmáticos e semânticos, podemos, por exemplo, enfocar o campo léxico e semântico da palavra family, já que todo o diálogo ocorreu devido ao fato de o passarinho amarelo buscar compreender o porquê de o gato Garfield ter comido os seus irmãozinhos. A palavra family, termo geral denominado nos estudos da lexicologia de hiperônimo, juntamente com a palavra brother, vocábulo mais específico, denominado hipônimo que aparece em dois momentos do texto, pode desencadear a produção do Esquema 01 adiante. Por campo semântico, compreendemos o conjunto dos empregos de uma palavra (ou sintagma ou lexia) pelos quais a palavra adquire uma carga semântica específica. Para delimitar esses empregos, faz-se o levantamento de todos os contextos que a palavra recebe num dado texto (GENOUVRIER e PEYTARD, 1985, p. 319).

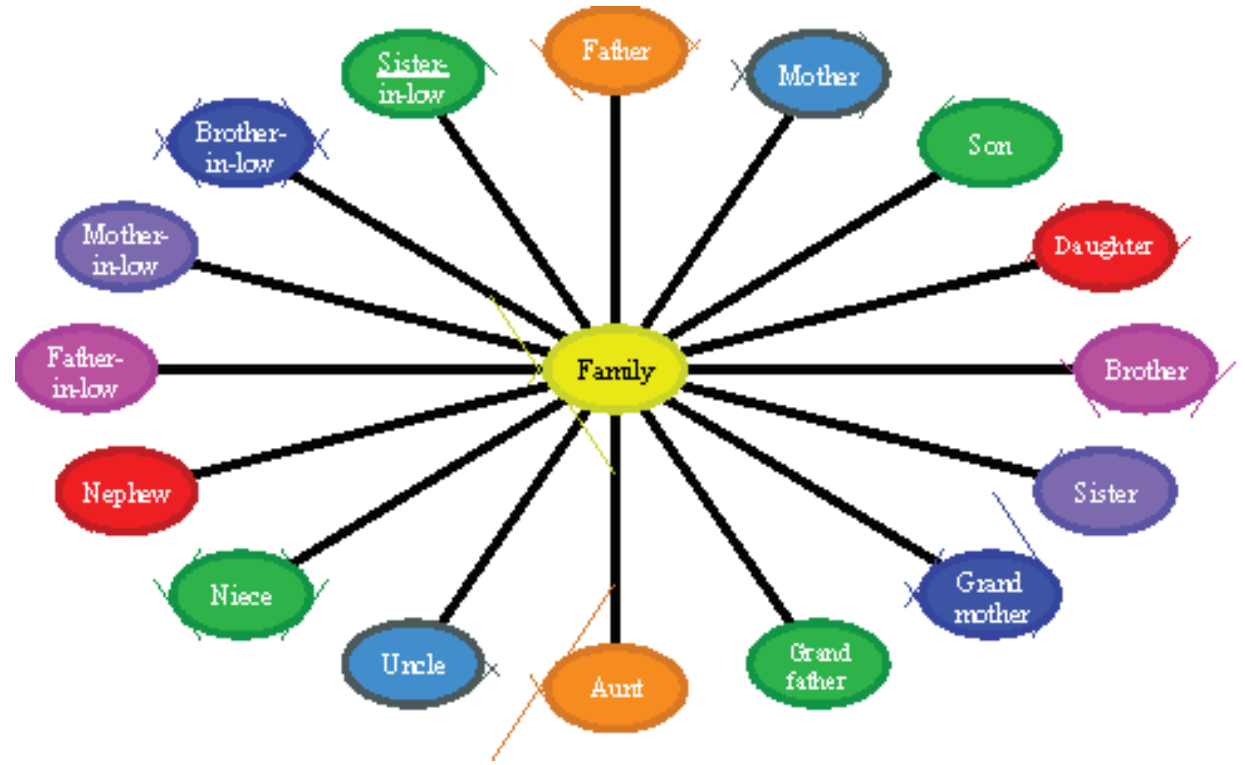

Esquema 1. 


\section{CONSIDERAÇÕES FINAIS}

As reflexões sobre os exercícios didáticos analisados neste trabalho contribuem para o ensino de língua inglesa como língua estrangeira. No entanto, como verificado a partir das investigações, apenas listas de palavras foram estudadas, cabendo aos estudantes memorizá-las. Os dados analisados revelam que em momento algum foi evidenciado o uso do vocabulário a partir de textos diversificados. Dessa forma, o tratamento que vem sendo dado ao ensino do vocabulário nos exercícios aplicados durante a prática de estágio supervisionado não tem fortalecido o ensino de línguas quanto ao aumento do léxico individual ou coletivo. A ênfase na formação da compreensão leitora, onde o texto é tido como processo cognitivo inferencial que considere e reconheça a contribuição dos processamentos cognitivos denominados botton up e top down na construção de sentido, geralmente é ignorada. A opção é, quase sempre, por uma postura tradicional quanto ao ensino de LE nas escolas públicas.

Um ponto a ser considerado, no entanto, é que uma estratégia para ampliar o vocabulário é a realização de atividades em que o aluno possa fazer associação com o que já se sabe. Extrair ou inferir um significado permite-lhe designar, alterar, organizar e incorporar novos conhecimentos a partir daqueles já armazenados e usados tradicionalmente. Isto deverá facilitar sua familiarização com novas estruturas lexicais que o possibilitam ampliar continuamente seu vocabulário.

Chamamos a atenção para o uso de hipertexto com multimídias como material de apoio pedagógico que podem intermediar a aprendizagem de léxico no ensino de língua inglesa. $\mathrm{O}$ uso de e-mail, MSN, assim também como uso da rede social Orkut e Livemocha, redes que possibilitam encontrar amigos e manter relacionamentos, participação em fóruns na plataforma moodle, o uso de blogs, skype, dentre outros gêneros eletrônicos, permitem ao aluno e ao professor empregarem o contexto virtual de forma autônoma e recíproca no ensino do vocabulário. Podendo colaborar para complementar a aprendizagem de línguas estrangeiras, oportunizando a socialização de conhecimentos de forma prazerosa, além de ser uma forma autêntica de comunicação, que proporciona uma interação real e dinâmica, um ambiente em que os estudantes poderão aprender as palavras que realmente os interessam.

Destacamos, ainda, que o vocabulário é elemento primordial no ensinoaprendizagem de uma língua estrangeira. A língua não apenas se reflete no léxico, mas é o próprio léxico que distingue uma língua de outra, pois ele representa a cosmovisão e o arcabouço cultural, linguístico e ideológico de um grupo. Trabalhar com o vocabulário implica vivenciar um pouco a experiência cultural do outro em armazenar e compreender seu próprio universo cultural. 


\section{REFERÊNCIAS BIBLIOGRÁFICAS}

BASILIO, M. (2007) Teoria lexical. São Paulo: Ática.

CERQUEIRA, M. S. (2010) Atividade versus exercício: concepções teóricas e a prática da produção textual no ensino de língua portuguesa. In: Trabalhos em Linguística Aplicada. vol. 49 nº. 1, Campinas jan./jun. p. 129-143.

FERREIRA, M. C. (2009) Campos léxico-semânticos e o ensino de vocabulário de segunda língua. In: Revista Prolíngua. Jul./Dez., p. 38-47.

GATTOLIN, S. R. B. (2006) O ensino de vocabulário no livro didático e na voz do professor. In: Lucia Rottava, Sulany Silveira dos Santos (orgs.). Ensino e aprendizagem de Linguas: língua estrangeira. Ijuí: Editora Unijuí, p. 139-156.

GENOUVRIER, E.; PEYTARD, J. (1985) Linguística e ensino do português. Coimbra: Livraria Almedina.

GONÇALVES, A. V. BAZARIM, M (2009) (orgs.). Interação, gênero, e letramento: a (re) escrita em foco. São Carlos: editora ClaraLuz.

KAMIL, M. L. HIEBERT, E. H. (2005) Teaching and Learning vocabulary. In:Elfrieda H. Hiebert e Michael L. Kamil. Teaching and Learning vocabulary: Bringing research to practice. London, Lawrence Erlbaum associates, p. 1-23.

JÚNIOR, R. M. L. (2010) Uma investigação dos efeitos do ensino explícito da pronúncia na aula de inglês como língua estrangeira. In: Revista brasileira de Linguística Aplicada, Belo Horizonte, v.10, n ${ }^{\circ} .3$, p.747-771.

MELO, L. C. de. (2011) Relatórios de estágio supervisionado em ensino de língua inglesa: práticas autoreflexivas de escrita. 2011. Dissertação (Mestrado em Ensino de Língua e Literatura) - Universidade Federal do Tocantins (UFT), Araguaína.

NAGY, W. (2005) Why vocabulary instruction needs to be long-term and comprehensive. In: Elfrieda H. Hiebert e Michael L. Kamil. Teacbing and Learning vocabulary: Bringing research to practice. London, Lawrence Erlbaum associates, p. 27-44.

PROCÓPIO, R. B. SOUZA, P. N. (2009) Os recursos visuais no ensino-aprendizagem de vocabulário em língua estrangeira. In: Maringá, v. 31, n² 2, p. 139-146

SCARAMUCCI, M. V. R. (2008) A competência lexical de alunos universitários aprendendo a ler inglês como língua estrangeira. In: Matilde V. R. Scaramucci e Sandra R. B. Gattolin (orgs.). Pesquisas sobre vocabulário em lingua estrangeira. Campinas, SP: Mercado de Letras, p. 73-95.

SCHMITT, N. (2000) Vocabulary in Language Teaching. Cambridge University Press.

SCOTT, J. A. (2005) Creating opportunities to acquire new word meanings from text. In: Elfrieda H. Hiebert e Michael L. Kamil. Teaching and Learning vocabulary: Bringing research to practice. London, Lawrence Erlbaum associates, p. 69-91.

SIGNORINI, I. (2007) Significados da inovação no ensino de língua portuguesa e na formação de professores. Inês Signorini (org.). Campinas, SP: Mercado de Letras. 
SOARES, T. S. R. CONCEIÇÃO, M. P. (2010) Crenças e ações do professor na sala de aula: um processo de perpetuação de abordagens tradicionais de ensino de vocabulário em língua estrangeira? In: Kleber Aparecido da Silva: Ensinar e aprender linguas na contemporaneidade: linhas e entrelinhas. Campinas: Pontes Editores, p.113-129.

SOUSA, L. F. de. (2010) Um novo olhar sobre o ensino de vocabulário. In: Vera Lúcia Menezes de Oliveira e Paiva (org.). Práticas de ensino e aprendizagem de Inglês com foco na autonomia. Campinas, SP, 3 Edição: Pontes, p. 51-82

TOMITCH, L. M. B. (2009) O ensino de vocabulário em leitura no livro didático de língua estrangeira. In: Renildes Dias e Vera Lúcia Lopes Cristovão (orgs.). O livro didático de língua estrangeira: múltiplas perspectivas. Campinas, São Paulo: Mercado de Letras, p. 121-148.

UR, P. (1996) Teaching vocabulary. In: Penny Ur. A course in language teaching: practice and theory. Cambridge University Press.

WIDDOWSON, H. G. (2004) Text, context, pretext: critical Issues in discourse analysis. Blackwell Publishing.

Recebido: 08/07/2011

Aceito: 20/04/2012 